\title{
MEASUREMENT OF ATMOSPHERIC ELEMENTAL CARBON: REAL-TIME DATA FOR LOS ANGELES DURING SUMMER 1987
}

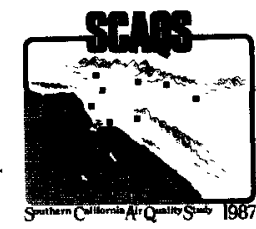

\author{
K. M. Adams, L. I. Davis, JR and S. M. JaPar \\ Ford Motor Company, Scientific Research Staff, Dearborn, MI 48121-2053, U.S.A. \\ D. R. FINLEY
}

University of Michigan, Department of Atmospheric, Oceanic, and Space Sciences, Ann Arbor, MI 481092143, U.S.A.

and

R. A. Cary

Sunset Laboratory, 2017 19th Avenue, Forest Grove, OR 97116, U.S.A.

(First received 21 February 1989 and in final form 12 September 1989)

\begin{abstract}
Two fundamentally different techniques for measuring atmospheric elemental carbon (EC) aerosol were compared to validate the methods. One technique, photoacoustic spectroscopy, was used to measure the optical absorption $(\lambda=514.5 \mathrm{~nm})$ of in situ atmospheric aerosol in real time. This optical absorption can be converted to EC concentration using the appropriate value of the absorption crosssection for $\mathrm{C}$, so that a comparison could be made with the second technique, thermal-optical analysis of filter-collected samples, which measures the collected EC by combustion. Solvent extraction of the filter samples prior to the thermal analysis procedure was required to minimize errors due to pyrolysis of organic carbon. Excellent 1:1 correlation of atmospheric EC concentrations resulted for measurements by the photoacoustic method vs the thermal method over coincident sampling times. The linear regression gave $y=1.006( \pm 0.056) x+0.27( \pm 0.56)$ with $r=0.945(n=41)$, where $y$ is the photoacoustic EC concentration and $x$ is the thermal elemental carbon concentration, both in $\mu \mathrm{g} \mathrm{m}^{-3}$. This data set was collected in Los Angeles as part of the Southern California Air Quality Study (SCAQS) during the summer 1987, and supplements the results of an earlier, more limited data set taken in Dearborn, MI. The diurnal variability of EC aerosol in Los Angeles during SCAQS, as determined by photoacoustic spectroscopy, is discussed.
\end{abstract}

Key word index: Atmospheric carbon, black carbon, elemental carbon, particulate carbon, photoacoustic, spectrophone, atmospheric optics, visibility, light absorption, optical absorption.

\section{INTRODUCTION}

Atmospheric EC aerosol (Wolff and Klimisch, 1981; Goldberg, 1985) has been measured by two fundamentally different techniques, and a comparison is presented in this paper in order to help establish a standard, accepted method for the measurement of this combustion-generated atmospheric pollutant. Specifically, an optical technique, photoacoustic spectroscopy (Pao, 1977; Rosencwaig, 1980), which measures optical absorption of in situ atmospheric samples (Adams, 1988; Adams et al., 1989), is compared with a thermal analysis technique (Adams et al., 1989) which measures $\mathrm{C}$ concentration from filter-collected samples. Atmospheric aerosol optical absorption, shown to be due only to EC (Rosen et al., 1978; Yasa et al., 1979; Japar et al., 1986), can easily be converted to EC concentration with the appropriate value for the absorption cross-section for EC. Thus, atmospheric EC concentrations determined with the two techniques over coincident sampling periods can be evaluated.
A previous intercomparison study of several C measurement methods conducted in 1986 (Countess, 1990; Hering et al., 1990) was not able to demonstrate a generally-accepted accurate method for the measurement of atmospheric carbon concentration. Most methods for measuring atmospheric concentrations heretofore have involved variations of thermal techniques, and their main difficulty has been the separation of the $\mathrm{EC}$ from the organic carbon (OC). Some of OC can pyrolyze EC and thereby interfere with the correct measurement of both fractions. Procedures to minimize and/or correct for any pyrolysis distinguish the different thermal methodologies. It has recently been pointed out that under certain circumstances the oxidation of EC can be catalyzed at lower temperatures than expected also causing error in the analysis (Lin and Friedlander, 1988). Because of the fundamental similarity in methods being compared, assessment of the validity of these $\mathrm{C}$ measurement techniques has been subjective. By comparing two totally different techniques, a thermal method and a photoacoustic technique (Adams, 1988; Adams et al., 1989), the 
validity of the EC measurements by both methods can be evaluated more objectively.

The thermal analysis procedure chosen for this and our previous work (Adams et al., 1989) adjusts for pyrolysis by using an optical monitor similar to that of Johnson et al. (1981), and has been referred to more specifically as thermal-optical analysis. Solvent extraction prior to the thermal analysis has been added to remove most of the OC fraction in order to focus on an accurate measurement of EC concentration by minimizing pyrolysis errors. The term thermal/extraction is used throughout this paper to refer to this complete procedure; whenever the extraction step was omitted the procedure is referred to as the normal thermal analysis.

The photoacoustic spectroscopic technique, which measures acoustic pressure produced from the absorption of modulated light, has several advantages over other methods used to measure either optical absorption or concentration of atmospheric EC. One advantage is that other optical absorption methods have generally been based on light attenuation measurements usually done on filter-collected samples. These methods minimize problems associated with light scattering from the sample and filter, but they are not totally successful in measuring the optical absorption because of sample and sample-filter interactions (Szkarlat and Japar, 1981; Bennett and Patty, 1982; Clarke, 1982a,b). Another advantage of the photoacoustic technique (as well as other optical methods) over thermal techniques is that OC does not interfere with the optical absorption measurement of atmospheric EC(Rosen et al., 1978; Yasa et al., 1979; Japar et al., 1986) because it and other atmospheric aerosol species absorb negligibly in the visible. Finally, the photoacoustic method used in this study analyzes the atmospheric sample in situ, easily generating real-time data. Since nearly all $\mathrm{C}$ measurement methods analyze filter-collected samples, with the exception of the aethalometer (Hansen et al., 1982, 1984), they result in data integrated over several hours. The real-time in situ photoacoustic data, which consist of atmospheric optical absorption and EC concentration, can provide more information about atmospheric EC than any other method currently available. In addition, the optical absorption data are important to the evaluation of contributions of light absorbing species, such as $\mathrm{EC}$ aerosol, to visibility reduction and atmospheric radiation balances.

As part of the summer 1987 Southern California Air Quality Study (SCAQS), we have expanded our Dearborn MI data (Adams et al., 1989) to include a much larger Los Angeles data set, presented in this paper. Los Angeles provided very different atmospheric conditions than those in Dearborn to further test the photoacoustic instrumentation (e.g. higher EC concentrations, higher temperatures, different meteorology). Together the Los Angeles and Dearborn data demonstrate, we believe, the validity of in situ photoacoustic measurements of atmospheric EC.
EXPERIMENTAL

The photoacoustic data collection described here was done as part of the SCAQS program carried out in the summer of 1987. The photoacoustic instrumentation was located in a trailer at the Claremont, CA site, in the middle of the Los Angeles basin near the southwest base of the San Gabriel mountains. There were 10 sampling days: 19,24 June, 13, 14, 15 July, 27, 28, 29 August, 2, 3 September. For each of these days continuous measurements were taken over four time periods: (1) 0100-0500 (4 h); (2) 0600-1000 (4 h); (3) 1100 $1700(6 \mathrm{~h})$; and (4) $1800-2400(6 \mathrm{~h})$ PDT. On an additional day, 25 June, one sampling period from 0100 to $0500(4 \mathrm{~h})$ was obtained.

A description and schematic of the photoacoustic spectrometer used for this study have been provided previously (Adams et al., 1989). The visible light source was an argon ion laser operated at $\lambda=514.5 \mathrm{~nm}$ and an optical output power of $1.0 \mathrm{~W}$. For this experiment, a feedback circuit was developed to maintain the mechanical chopper frequency at the cell resonance frequency, which changes with ambient temperature. The circuit monitored the lock-in analyzer phase output and controlled the chopper frequency to maintain the signal phase at 90 degrees relative to the chopper. The instrument was calibrated for optical absorption with $500 \mathrm{ppb} \mathrm{NO}{ }_{2}$ during the hour between measurement periods, described above. Background checks were done every hour, on the hour, with humidified compressed air matched to the atmospheric humidity, and took $\sim 10 \mathrm{~min}$. Atmospheric air was sampled at a constant flow rate of $450 \mathrm{~cm}^{3} \mathrm{~min}^{-1}$. It was drawn through a $\mathrm{MnO}$, denuder (Adams et al., 1986) to remove atmospheric $\mathrm{NO}_{2}$; the denuder inlet was located $\sim 2 \mathrm{~m}$ above the ground and $30 \mathrm{~cm}$ from the outside wall of the trailer. The instrument signal was recorded in $\mu \mathrm{V}$ continuously on both a strip chart recorder and on a personal computer at a rate of one data point every $2 \mathrm{~s}$.

Reduction of the real-time photoacoustic measurements for comparison with EC concentrations determined from filter samples has been described (Adams et al., 1989). Integrated values of the continuous atmospheric photoacoustic signal in $\mu \mathrm{V}$ were calculated for $\sim 50 \mathrm{~min}$ time intervals between background measurements. An average background value for these intervals was calculated assuming linear drift and was subtracted from the atmospheric signal. The calibration factors were determined to account for the instrument sensitivity to humidity and temperature (Adams et al., 1989). Humidity compensation was attained by matching the humidity of the calibration gas with that of the atmosphere. Temperature compensation was achieved by correction of the calibration factors, measured at the beginning and end of each sampling period, using the average temperature (to $0.1^{\circ} \mathrm{C}$ ) of the $50 \mathrm{~min}$ intervals. The concentrations for each of these $\sim 50$ min segments were time-weighted to obtain average concentrations over the 4 or $6 \mathrm{~h}$ periods during which filter samples $\left(8^{\prime \prime} \times 10^{\prime \prime}\right.$ quartz fiber filters prefired in air at $600^{\circ} \mathrm{C}$ for $16 \mathrm{~h}$ ) were collected using a high volume sampler

The 24-h real-time plots of the photoacoustic data were obtained by integrating the raw data (one point every $2-\mathrm{s}$ ) over $30 \mathrm{~s}$ time intervals. The $30 \mathrm{~s}$ time segment was close to the estimated $25 \mathrm{~s}$ time constant of the sampling cell (Adams et al., 1989). Baseline values were extrapolated for each $30 \mathrm{~s}$ time interval by assuming linear drift between the hourly baseline measurements. Temperature corrections were applied to each $30 \mathrm{~s}$ interval by using a calibration factor calculated from the average temperature of the $30 \mathrm{~s}$ segment, as described above.

Thermal-optical analysis of the filter samples was done by Sunset Laboratory (Forest Grove, Oregon), and has been described in detail (Johnson et al., 1981; Adams et al., 1989). The normal procedure used by Sunset Laboratory corrects for pyrolysis of $O C$ by monitoring laser light transmitted through the filter sample during the thermal analysis. As in our previous study (Adams et al., 1989), this procedure was 
modified to include a solvent extraction step prior to the thermal analysis. A portion of each filter was soaked overnight in a $50-50(\mathrm{v} / \mathrm{v})$ mixture of $n$-propanol and toluene, then removed and dried. This extraction was done in order to eliminate most of the $\mathrm{OC}$, and thus minimize any pyrolysis error in the EC determination.

\section{RESULTS AND DISCUSSION}

\section{(A) Elemental carbon absorption coefficient}

Correlation was good for the optical absorption measured photoacoustically with EC concentrations determined by the thermal/extraction analysis of the filter-collected samples collected over corresponding time periods. The coefficients, and their standard errors, for this linear regression are given in the equation:

$$
\begin{aligned}
& y=10.06( \pm 0.56) x+2.7( \pm 5.6) \\
& r=0.945 \quad n=41
\end{aligned}
$$

where $y$ is the optical absorption in $10^{-5} \mathrm{~m}^{-1}$ (based on the $\mathrm{NO}_{2}$ calibration) and $x$ is the thermal/extracted EC concentration in $\mu \mathrm{g} \mathrm{m}^{-3}$.

These correlation results demonstrate that the two methods were both measuring atmospheric $\mathrm{EC}$ with high precision. The $y$-intercept, $2.7( \pm 5.6)$, is essentially zero within the uncertainty. The standard error in the slope is equivalent to the uncertainty in precision for both methods, i.e. $6 \%$ for the photoacoustic method and $5 \%$ for the thermal analysis.

The slope of the regression line gives an independent determination of the absorption coefficient for $\mathrm{EC}, 10.06( \pm 0.56) \mathrm{m}^{2} \mathrm{~g}^{-1}$ (at $\left.514.5 \mathrm{~nm}\right)$. This value is in excellent agreement with the accepted value of 9.5 $( \pm 1.5) \mathrm{m}^{2} \mathrm{~g}^{-1}$ at $514.5 \mathrm{~nm}$ (Japar et al., 1984) for the aerosol EC absorption coefficient. The accepted value was based on studies using a number of techniques, including photoacoustic spectroscopy, in laboratory and field settings to determine the optical properties of airborne EC. This agreement is a demonstration of the invariability of the elemental carbon absorption coefficient over a wide range of experimental conditions, and is evidence to presume accuracy for both the photoacoustic and thermal/extraction methods.

The value of $10 \mathrm{~m}^{2} \mathrm{~s}^{-1}(\lambda=514.5 \mathrm{~nm})$ was used for the absorption coefficient in the initial analysis of EC concentrations for the real-time data, and also for the final concentration values reported in this paper.

(B) Comparison of elemental carbon concentrations from photoacoustic and thermal analyses

The photoacoustic and thermal/extracted EC concentrations, for the 41 sampling periods described in the Experimental section, agree within the measurement errors listed in Table 1 . These $1 \sigma$ errors for both methods have been calculated as being equal to the precision error, which increases by a fixed percentage of the signal, plus a constant detection limit error, as detailed in the Table 1 footnotes. These measurement errors for the photoacoustically determined $\mathrm{C}$ concen- trations do not include the uncertainty associated with the absorption coefficient. This provides more restricted limits on the comparison of concentrations determined by the two methods. Only 11 of the 41 data points $(27 \%)$ differ by more than the $1 \sigma$ error, and only 1 out of 41 falls outside $3 \sigma$. The comparison is consistent with the probabilities of the normal distribution.

Scaling Equation (1) by a factor of 10 we have:

$$
y=1.006( \pm 0.056) x+0.27( \pm 0.56)
$$

where $y$ is the photoacoustic EC concentration and $x$ is the thermal/extracted EC concentration, both in $\mu \mathrm{g} \mathrm{m}^{-3}$. The data have been plotted in Fig. 1 along with the regression line. The error in the slope indicates $5.6 \%$ uncertainty in the $1: 1$ agreement. The standard error in the intercept, $\pm 0.56 \mu \mathrm{g} \mathrm{m}^{-3}$, is consistent with the average $1 \sigma$ error, $0.50( \pm 0.10)$, of the photoacoustic concentrations which have a slightly higher uncertainty than the thermal analysis uncertainties in Table 1.

For 26 of the samples, portions of the high-volume filters were analyzed for EC using the normal thermal analysis procedure without the solvent extraction, and the resulting concentrations do not agree with the photoacoustic concentrations to within the errors (Table 1). In this case, only four of the 26 sample periods fall within the $1 \sigma$ error for the photoacoustic measurement, and three of the 26 fall outside $3 \sigma$, which is inconsistent with normal distribution probabilities for 1:1 agreement. Linear regression results in the following coefficients:

$$
\begin{aligned}
& y=1.08( \pm 0.10) x+0.66( \pm 0.75) \\
& r=0.914 \quad n=26
\end{aligned}
$$

where $y$ is the photoacoustic EC concentration and $x$ is the thermal EC concentration determined from non-extracted filter samples, both in $\mu \mathrm{g} \mathrm{m}^{-3}$. The linear regression errors in both the slope and intercept are larger than those in Equation (2) indicating considerably more scatter about the regression line than in the extraction case. The error in the intercept, $\pm 0.75 \mu \mathrm{g} \mathrm{m}^{-3}$, is also significantly greater than the average $1 \sigma$ error, $0.49( \pm 0.11) \mu \mathrm{g} \mathrm{m}^{-3}$ for the corresponding 26 photoacoustic concentrations in Table 1. In addition to more scatter, a systematic overcorrection for pyrolysis is suggested with this data set both by the slope, which is $7 \%$ greater than in the extraction case, and by the intercept, which is $0.4 \mu \mathrm{g} \mathrm{m}^{-3}$ greater than in the extraction case, although still indistinguishable from zero within the uncertainty.

Comparison with the normal thermal data without the solvent extraction demonstrates the difficulty of separating the $\mathrm{OC}$ and $\mathrm{EC}$ in a thermal procedure for a correct analysis of each fraction. The solvent extraction step was included to minimize error due to pyrolysis of the $\mathrm{OC}$, and the improved result suggests a new thermal analysis procedure to obtain correct $\mathrm{OC}$ and $\mathrm{EC}$ concentrations from filter samples. Two 
Table 1. Summary of elemental carbon concentrations in $\mu \mathrm{g} \mathrm{m}^{-3}$

\begin{tabular}{|c|c|c|c|c|c|c|}
\hline Date & Period & Time & $\begin{array}{l}\text { Photoacoustic } \\
\text { period-average } \\
\text { concentration }\end{array}$ & $\begin{array}{l}\text { Thermal/extracted } \\
\text { period-average } \\
\text { concentration }\end{array}$ & $\begin{array}{l}\text { Thermal } \\
\text { period-average } \\
\text { concentration }\end{array}$ & $\begin{array}{l}\text { Photoacoustic } \\
\text { day-average } \\
\text { concentration }\end{array}$ \\
\hline $6-19-87$ & $\begin{array}{l}1 \\
2 \\
3 \\
4\end{array}$ & $\begin{array}{l}0100-0500 \\
0600-1000 \\
1100-1700 \\
1800-2400\end{array}$ & $\begin{array}{l}2.47 \pm 0.45^{*} \\
4.22 \pm 0.55 \\
2.74 \pm 0.46 \\
1.98 \pm 0.42\end{array}$ & $\begin{array}{l}2.47 \pm 0.36 \dagger \\
4.27 \pm 0.46 \\
3.15 \pm 0.31 \\
1.92 \pm 0.23\end{array}$ & $\begin{array}{l}1.79 \pm 0.33 \dagger \\
3.01 \pm 0.40 \\
2.42 \pm 0.27 \\
1.57 \pm 0.21\end{array}$ & 2.74 \\
\hline $6-25-87$ & $\begin{array}{l}1 \\
2 \\
3 \\
4 \\
1\end{array}$ & $\begin{array}{l}0100-0500 \\
0600-1000 \\
1100-1700 \\
1800-2400 \\
0100-0500\end{array}$ & $\begin{array}{l}1.78 \pm 0.41 \\
2.98 \pm 0.48 \\
5.40 \pm 0.62 \\
2.00 \pm 0.42 \\
2.39 \pm 0.44\end{array}$ & $\begin{array}{l}1.06 \pm 0.29 \\
2.76 \pm 0.40 \\
5.06 \pm 0.41 \\
2.00 \pm 0.26 \\
1.78 \pm 0.32\end{array}$ & $\begin{array}{l}1.18 \pm 0.29 \\
2.04 \pm 0.36 \\
2.98 \pm 0.31 \\
1.33 \pm 0.23 \\
1.50 \pm 0.31\end{array}$ & 3.15 \\
\hline $7-13-87$ & $\begin{array}{l}1 \\
2 \\
3 \\
4\end{array}$ & $\begin{array}{l}0100-0500 \\
0600-1000 \\
1100-1700 \\
1800-2400\end{array}$ & $\begin{array}{l}0.87 \pm 0.35 \\
5.61 \pm 0.64 \\
4.04 \pm 0.54 \\
1.93 \pm 0.42\end{array}$ & $\begin{array}{l}1.00 \pm 0.27 \\
5.74 \pm 0.52 \\
4.05 \pm 0.36 \\
1.70 \pm 0.23\end{array}$ & $\begin{array}{l}0.68 \pm 0.25 \\
4.50 \pm 0.46 \\
2.92 \pm 0.30 \\
1.61 \pm 0.23\end{array}$ & 3.01 \\
\hline $7-14-87$ & $\begin{array}{l}1 \\
2 \\
3 \\
4\end{array}$ & $\begin{array}{l}0100-0500 \\
0600-1000 \\
1100-1700 \\
1800-2400\end{array}$ & $\begin{array}{l}2.07 \pm 0.42 \\
3.19 \pm 0.49 \\
4.60 \pm 0.58 \\
1.82 \pm 0.41\end{array}$ & $\begin{array}{l}1.74 \pm 0.33 \\
2.89 \pm 0.38 \\
4.56 \pm 0.38 \\
1.70 \pm 0.24\end{array}$ & $\begin{array}{l}1.52 \pm 0.32 \\
2.43 \pm 0.35 \\
2.43 \pm 0.27 \\
1.30 \pm 0.22\end{array}$ & 2.97 \\
\hline $7-15-87$ & $\begin{array}{l}1 \\
2 \\
3 \\
4\end{array}$ & $\begin{array}{l}0100-0500 \\
0600-1000 \\
1100-1700 \\
1800-2400\end{array}$ & $\begin{array}{l}1.42 \pm 0.39 \\
1.92 \pm 0.42 \\
3.12 \pm 0.49 \\
2.13 \pm 0.43\end{array}$ & $\begin{array}{l}1.26 \pm 0.29 \\
1.91 \pm 0.32 \\
3.45 \pm 0.32 \\
1.97 \pm 0.25\end{array}$ & $\begin{array}{l}0.81 \pm 0.27 \\
1.03 \pm 0.28 \\
2.38 \pm 0.27 \\
1.02 \pm 0.21\end{array}$ & 2.24 \\
\hline $8-27-87$ & $\begin{array}{l}1 \\
2 \\
3 \\
4\end{array}$ & $\begin{array}{l}0100-0500 \\
0600-1000 \\
1100-1700 \\
1800-2400\end{array}$ & $\begin{array}{l}2.34 \pm 0.44 \\
6.50 \pm 0.69 \\
7.03 \pm 0.72 \\
2.76 \pm 0.47\end{array}$ & $\begin{array}{l}1.78 \pm 0.30 \\
6.06 \pm 0.55 \\
4.79 \pm 0.35 \\
2.46 \pm 0.28\end{array}$ & $\begin{array}{l}5.75 \pm 0.54 \\
3.91 \pm 0.35\end{array}$ & 4.61 \\
\hline $8-28-87$ & $\begin{array}{l}1 \\
2 \\
3 \\
4\end{array}$ & $\begin{array}{l}0100-0500 \\
0600-1000 \\
1100-1700 \\
1800-2400\end{array}$ & $\begin{array}{l}3.02 \pm 0.48 \\
6.36 \pm 0.68 \\
6.92 \pm 0.72 \\
2.75 \pm 0.46\end{array}$ & $\begin{array}{l}2.85 \pm 0.39 \\
5.67 \pm 0.52 \\
5.46 \pm 0.43 \\
1.97 \pm 0.26\end{array}$ & & 4.67 \\
\hline $8-29-87$ & $\begin{array}{l}1 \\
2 \\
3 \\
4\end{array}$ & $\begin{array}{l}0100-0500 \\
0600-1000 \\
1100-1700 \\
1800-2400\end{array}$ & $\begin{array}{l}3.53 \pm 0.51 \\
4.20 \pm 0.55 \\
4.23 \pm 0.55 \\
2.43 \pm 0.45\end{array}$ & $\begin{array}{l}2.81 \pm 0.38 \\
3.72 \pm 0.42 \\
2.87 \pm 0.30 \\
1.89 \pm 0.24\end{array}$ & & 3.55 \\
\hline $9-02-87$ & $\begin{array}{l}1 \\
2 \\
3 \\
4\end{array}$ & $\begin{array}{l}0100-0500 \\
0600-1000 \\
1100-1700 \\
1800-2400\end{array}$ & $\begin{array}{l}1.57 \pm 0.39 \\
3.95 \pm 0.54 \\
2.67 \pm 0.46 \\
3.90 \pm 0.53\end{array}$ & $\begin{array}{l}1.34 \pm 0.28 \\
5.12 \pm 0.49 \\
3.02 \pm 0.34 \\
3.31 \pm 0.32\end{array}$ & $3.34 \pm 0.35$ & 3.04 \\
\hline 9-03-87 & $\begin{array}{l}1 \\
2 \\
3 \\
4\end{array}$ & $\begin{array}{l}0100-0500 \\
0600-1000 \\
1100-1700 \\
1800-2400\end{array}$ & $\begin{array}{l}2.53 \pm 0.45 \\
7.33 \pm 0.77 \\
3.73 \pm 0.53 \\
1.55 \pm 0.39\end{array}$ & $\begin{array}{l}2.27 \pm 0.37 \\
7.42 \pm 0.61 \\
3.67 \pm 0.35 \\
1.22 \pm 0.25\end{array}$ & $\begin{array}{l}6.96 \pm 0.59 \\
1.12 \pm 0.25\end{array}$ & 3.62 \\
\hline
\end{tabular}

* The error for the photoacoustic carbon concentration is equal to $\pm 6 \%$ (the uncertainty in the precision) plus $0.3 \mu \mathrm{g} \mathrm{m}^{-3}$ (the detection limit for signal-to-noise of 1).

$\dagger$ The error for the thermal analysis of the filters is equal to $\pm 5 \%$ (the uncertainty in the precision) plus $0.2 \mu \mathrm{g} \mathrm{cm}^{-2}$ (the detection limit).

separate analysis operations would be required, i.e. the EC concentration could be determined by the thermal analysis of an extracted filter sample, total $C$ would be determined by thermal analysis of an non-extracted portion of the same filter, and OC would be determined by the difference. The high quality $\mathrm{EC}$ results of both this Los Angeles and the previous Dearborn data sets were dependent on the extraction prior to the thermal analysis, however for general application further testing should be considered.
Since the two measurement techniques, photoacoustic spectroscopy and thermal/extraction, are based on entirely different principles, their excellent agreement provides strong evidence for the validity of both experimental methods for the measurement of atmospheric EC aerosol. The data in Table 1 and Fig. 1 provide a supplement in excellent agreement with the validation data collected in Dearborn (Adams et al., 1989). The concentrations of atmospheric EC from the smaller Dearborn data set $(n=14)$ 


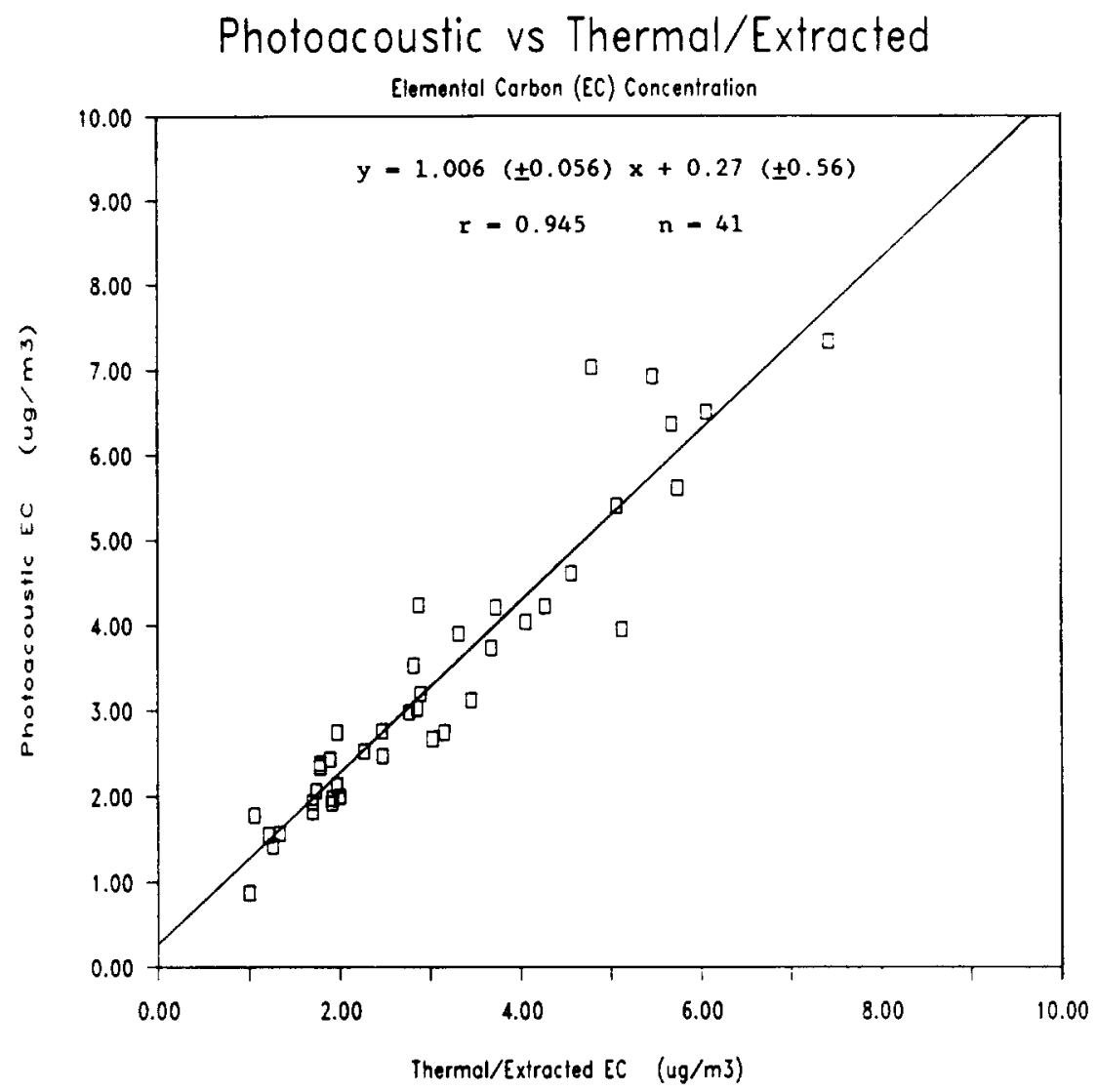

Fig. 1. Correlation of photoacoustic vs thermal/extracted atmospheric elemental carbon concentrations.

ranged from $0.3 \mu \mathrm{g} \mathrm{m}^{-3}$, the photoacoustic detection limit, to $\sim 2 \mu \mathrm{g} \mathrm{m}^{-3}$, and this has been extended to $\sim 8 \mu \mathrm{g} \mathrm{m}^{-3}$ with the Los Angeles data $(n=41)$.

(C) Diurnal variation in elemental carbon concentrations for Los Angeles in summer 1987

Continuous, real-time EC concentrations determined photoacoustically are shown for two days in Figs 2 (a) and (b). These 24-h plots are typical, and show examples of slow drifts in the $C$ concentration and transient features of varying intensity and time duration.

Some consistent diurnal patterns were observed in the real-time photoacoustic data for the 10 full days of measurements. The early morning period 1 and the evening period 4 always had the lowest period-average $C$ concentrations, whereas the highest period-average concentration during the daily cycle was either in the late morning period 2 or the afternoon period 3 , as can be seen in Table 1. Transient features in the real-time data were rare during periods 1 and 4 . At the beginning of period 2 , the $\mathrm{C}$ concentration generally showed an increase in the first hour (6:00 a.m.) which coincided with the daily escalation of industrial activity and the morning rush hour traffic and with the onset of wind out of the southwest. The afternoon rush hour was apparent from a high $\mathbf{C}$ concentration in period 3, often displayed by a second peak in the daily concentrations as in Figs 2 (a) and (b). Toward the end of period 3 and the beginning of period 4 , the concentration decreased as industrial and traffic activities tapered off. These observations are confirmed in Table 2 by the average hourly values for the elemental carbon concentrations over the 10 sampling days. A number of transient features were often observed during periods 2 and 3 , as can be seen particularly in Fig. 2 (a). During the daylight hours the wind generally had a constant speed and was out of the southwest, and the transient $\mathrm{C}$ concentration peaks were likely associated with local sources within a few miles. Transient peaks of a short time duration, e.g. $5 \mathrm{~min}$, were often associated with a local event, such as a diesel-powered vehicle driving within $30 \mathrm{~m}$ of the site. The wind direction was from the east (Santa Ana winds) on only one afternoon (2 September); when it abruptly changed to out of the southwest, an increase in the $\mathbf{C}$ concentration was noted. $\mathbf{A}$ more rigorous 


\section{PHOTOACOUSTIC SPECTROSCOPY DATA}

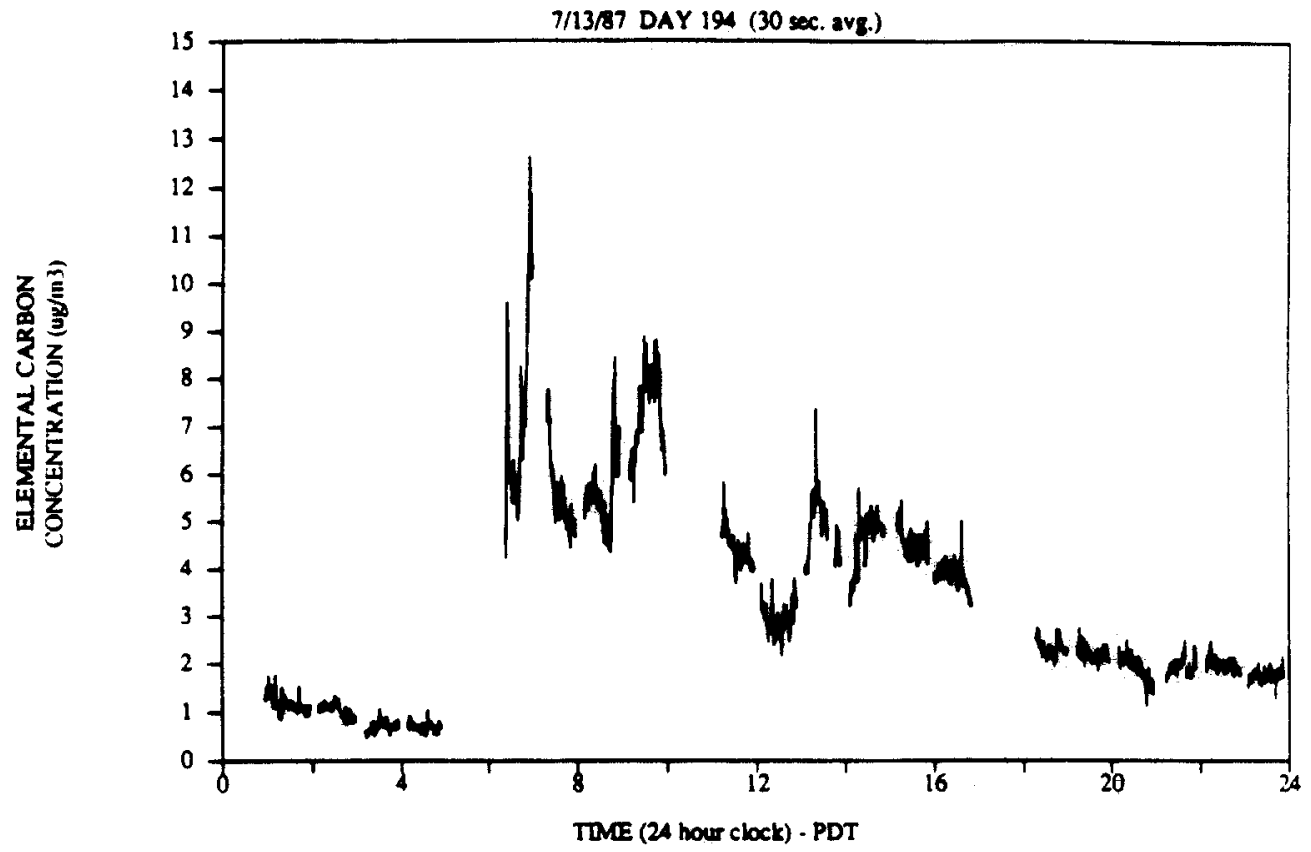

\section{PHOTOACOUSTIC SPECTROSCOPY DATA}

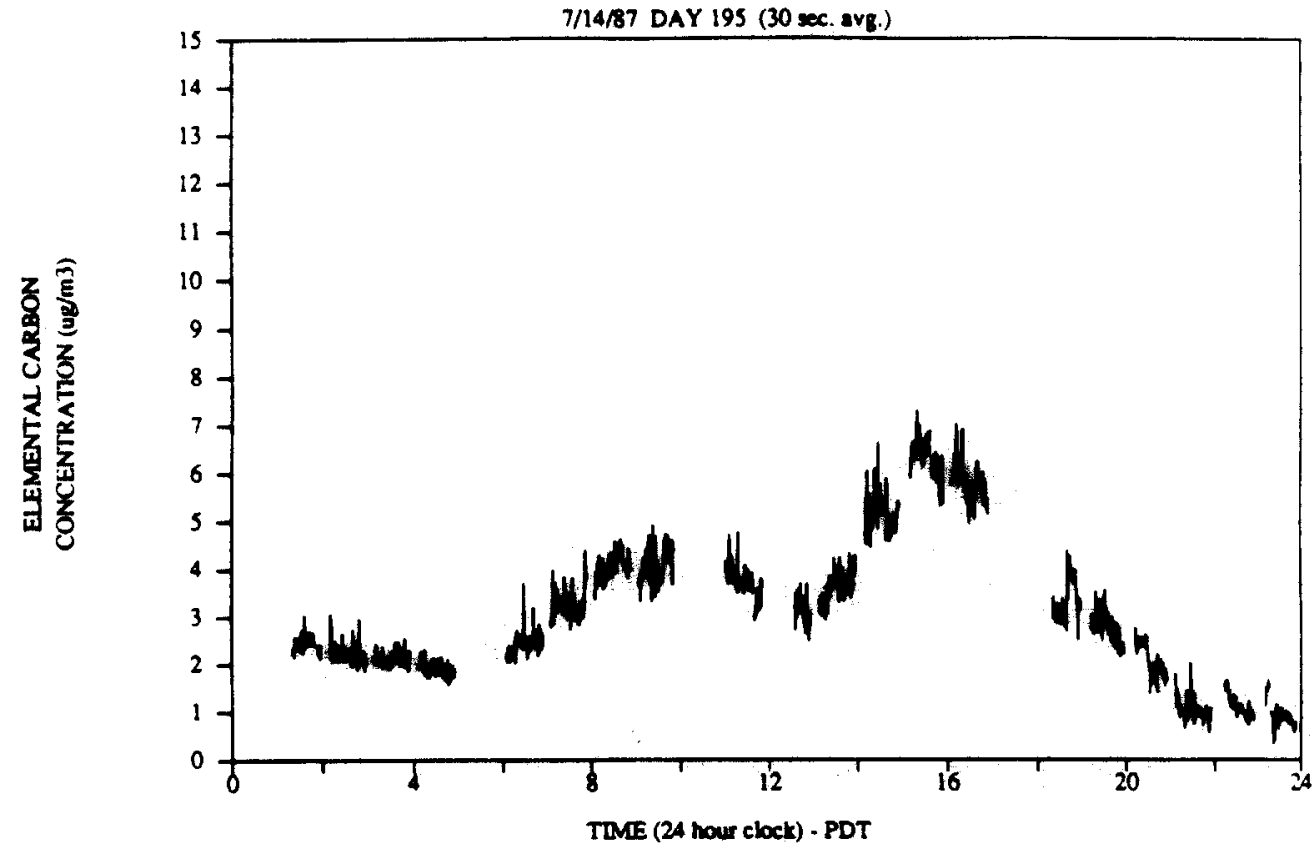

Fig. 2. Real-time atmospheric elemental carbon concentrations for Claremont CA (a) on 13 July 1987 and (b) on 14 July 1987. (Note: as explained in the Experimental section, calibrations were done during the four $\sim 1 \mathrm{~h}$ breaks in the data, and backgrounds were checked during the 10-15 min gaps at the beginning of each hour.) 
Table 2. Hourly summary of average elemental carbon concentrations $\left(\mu \mathrm{g} \mathrm{m}^{-3}\right)$ for the 10 sampling days

\begin{tabular}{lcc}
\hline $\begin{array}{l}\text { Starting } \\
\text { hour }\end{array}$ & $\begin{array}{c}\text { Average } \\
\text { concentration }\end{array}$ & $\begin{array}{c}\text { Standard } \\
\text { deviation }\end{array}$ \\
\hline 1 & 2.02 & 0.58 \\
2 & 2.17 & 0.64 \\
3 & 2.13 & 0.85 \\
4 & 2.37 & 0.90 \\
6 & 4.47 & 2.03 \\
7 & 5.09 & 2.43 \\
8 & 4.32 & 1.14 \\
9 & 4.59 & 2.00 \\
11 & 4.69 & 1.46 \\
12 & 4.23 & 1.28 \\
13 & 4.31 & 1.79 \\
14 & 4.54 & 2.11 \\
15 & 4.36 & 1.79 \\
16 & 4.58 & 1.62 \\
18 & 3.13 & 0.62 \\
19 & 2.59 & 0.72 \\
20 & 2.19 & 0.76 \\
21 & 2.16 & 0.78 \\
22 & 2.08 & 0.79 \\
23 & 2.05 & 0.75 \\
\hline & & \\
\hline
\end{tabular}

analysis of these real-time data, such as modeling and source apportionment, is beyond the scope of this paper.

The range in values for EC concentrations measured in this study can be stated according to defined time intervals. For the real-time data, i.e. $30 \mathrm{~s}$ average, the carbon concentration peaked as high as $17.2 \mu \mathrm{g} \mathrm{m}^{-3}$ during a transient on 2 September at 6:53 a.m. (during period 2), and was measured as low as $0 \mu \mathrm{g} \mathrm{m}^{-3}$ (where $0.3 \mu \mathrm{g} \mathrm{m}^{-3}$ is the detection limit) on a few occasions, however the most frequent occurrence of levels near the detection limit were observed on 2 September intermittently from $\sim 12: 45$ to 3:30 p.m. (in period 3) during the Santa Ana winds. For the hourly averages (actually the $\leq 50 \mathrm{~min}$ intervals between baseline measurements), the highest average concentration was $9.1 \mu \mathrm{g} \mathrm{m}^{-3}$ between 7 and 8 a.m. (during period 2) on both 28 August and 3 September, and the lowest was $0.7 \mu \mathrm{g} \mathrm{m}^{-3}$ between both 3-4 and 4-5 a.m. (during period 1) on $13 \mathrm{July.}$ For the periods between calibrations, all the periodaverage EC concentrations for the study are listed in Table 1. The highest period-average concentration was $7.3 \mu \mathrm{g} \mathrm{m}^{-3}$ for period 2 on 3 September, and the lowest was $0.9 \mu \mathrm{g} \mathrm{m}^{-3}$ for period 1 on $13 \mathrm{July}$. Values for the average of concentrations measured over a 24-h day are also listed in Table 1 . The daily average concentration was relatively invariable, ranging only over a factor of 2 , from the highest concentration, $4.7 \mu \mathrm{g} \mathrm{m}^{-3}$ on 28 August, to the lowest, $2.2 \mu \mathrm{g} \mathrm{m}^{-3}$ on 15 July.

\section{CONCLUSION}

Several findings from this comparative study are summarized as follows.

\section{(1) Validation of an optical absorption method}

The results from Los Angeles presented here further validate the application of photoacoustic spectroscopy for real-time, in situ measurements of atmospheric EC aerosol. The instrument has been tested in two locations, Dearborn (Adams et al., 1989) and Los Angeles, with different atmospheric environments, particularly the average levels of $\mathrm{EC}, \leqslant 2$ and $\leqslant 8 \mu \mathrm{g} \mathrm{m}^{-3}$, respectively. The photoacoustic technique has a number of unique advantages, i.e. the measurements are in real time, the aerosol is measured in situ, optical absorption is measured directly, and the data are easily converted to concentrations.

\section{(2) Validation of a thermal analysis method}

The atmospheric EC concentrations inferred from photoacoustic and measured using thermal/extraction techniques are linear within $5.6 \%$ uncertainty demonstrating the agreement of two fundamentally different methods. The correlation with measurements using the normal thermal technique has greater uncertainty $(10 \%)$. When the thermal procedure was modified to include a solvent extraction step to minimize error due to pyrolysis of $\mathrm{OC}$, the linear regression coefficients had less scatter and the absorption coefficient determined from the slope was in better agreement with the accepted value. A systematic overcorrection for pyrolysis by the normal thermal analysis is suggested.

\section{(3) Verification of the optical absorption coefficient}

The accepted value of $9.5( \pm 1.5) \mathrm{m}^{2} \mathrm{~g}^{-1}$ at $514.5 \mathrm{~nm}$ (Japar et al., 1984), for the absorption cross-section of atmospheric EC aerosol is further substantiated by the results of this study. From the slope of the linear regression line in Equation (1), a value of 10.06 $( \pm 0.56) \mathrm{m}^{2} \mathrm{~g}^{-1}$ has been determined.

(4) Confirmation for the source of aerosol optical absorption

Others (Rosen et al., 1978; Yasa et al., 1979; Japar et al., 1986) have found atmospheric EC to be the only source of aerosol optical absorption. Organic carbon and inorganic oxides have been considered, but their contributions to visible light absorption in the atmosphere have been deemed insignificant. For this study, the excellent agreement between the optical and nonoptical method for EC determination is consistent with a lack of significant optical absorption by other aerosol species.

Acknowledgements-The authors would like to thank several people, Drs R. H. Hammerle, J. M. Norbeck, W. R. Pierson and $M$. Shelef, for their support throughout the course of this project. Thanks are also extended to Ms S. J. Rudy for her 
help in the data reduction. Appreciation should also be noted for the support of the SCAQS coordinators, including the Coordinating Research Council, and in particular Dr S. V. Hering presently with Sonoma Technology and Dr D. R. Lawson with the California Air Resources Board.

\section{REFERENCES}

Adams K. M. (1988) Real-time, in situ measurements of atmospheric optical absorption in the visible via photoacoustic spectroscopy. I. Evaluation of photoacoustic cells. Appl. Opt. 27, 4052-4056.

Adams K. M., Davis L. I., Jr., Japar S. M. and Pierson W. R. (1989) Real-time, in situ measurements of atmospheric optical absorption in the visible via photoacoustic spectroscopy. II. Validation for atmospheric elemental carbon aerosol. Atmospheric Environment 23, 693-700.

Adams K. M., Japar S. M. and Pierson W. R. (1986) Development of a $\mathrm{MnO}_{2}$-coated, cylindrical denuder for removing $\mathrm{NO}_{2}$ from atmospheric samples. Atmospheric Environment 20, 1211-1215.

Bennett C. A., Jr. and Patty R. R. (1982) Monitoring particulate carbon collected on Tefion filters: an evaluation of photoacoustic and transmission techniques. Appl. Opt. 21, 371-374.

Clarke A. D. (1982a) Integrating sandwich: A new method of the light absorption coefficient for atmospheric particles. Appl. Opt. 21, 3011-3020.

Clarke A. D. (1982b) Effects of filter internal reflection coefficient on light absorption measurements made using the integrating plate method. Appl. Opt. 21, 3021-3031.

Countess R. J. (1990) Interlaboratory analyses of carbonaceous aerosol samples. Aerosol Sci. Technol. (submitted).

Goldberg E. D. (1985) Black Carbon in the Environment. John Wiley, New York.

Hansen A. D. A., Rosen H. and Novakov T. (1982) Real-time measurement of the absorption coefficient of aerosol particles. Appl. Opt. 21, 3060-3062.
Hansen A. D. A., Rosen H. and Novakov T. (1984) The aethalometer--an instrument for the real-time measurement of optical absorption by aerosol particles. Sci. total Envir. 36, 191-196.

Hering S. V., Appel B. R., Cheng W., Salaymeh F., Cadle S. H., Mulawa P. A., Cahill T. A., Eldred R. A., Surovik M. Fitz D., Howes J. E., Knapp K. T., Stockburger L., Turpin B. J., Huntzicker J. J., Zhang X.-Q. and McMurry P. H. (1990) Comparison of sampling methods for carbonaceous aerosols in ambient air. Aerosol Sci. Technol. (submitted).

Japar S. M., Szkarlat A. C. and Pierson W. R. (1984) The determination of the optical properties of airborne particle emissions from diesel vehicles. Sci. total Envir. 36, 121-130.

Johnson R. L., Shah J. J., Cary R. A. and Huntzicker J. J. (1981) An automated thermal-optical method for the analysis of carbonaceous aerosol. In ACS Symposium Series, No. 167, Atmospheric Aerosol: Source/Air Quality Relationships (edited by E. S. Macias and P. K. Hopke), pp. 223-233.

Lin C. and Friedlander S. K. (1988) A note on the use of glass fiber filters in the thermal analysis of carbon containing aerosols. Atmospheric Environment 22, 605-607.

Pao Y.-H. (Ed.) (1977) Optoacoustic Spectroscopy and Detection. Academic Press, New York.

Rosen H., Hansen A. D. A., Gundel L. and Novakov T. (1978) Identification of the optically absorbing component in urban aerosols. Appl. Opt. 17, 3859-3861.

Rosencwaig A. (1980) Photoacoustics and photoacoustic spectroscopy. In Chemical Analysis: A Series of Monographs on Analytical Chemistry and its Applications, Volume 57 (edited by P. J. Elving and J. D. Winefordner, Editor Emeritus: I. M. Kolthoff). John Wiley, New York.

Szkarlat A. C. and Japar S. M. (1981) Light absorption by aerosols: comparison of integrating plate and spectrophone techniques. Appl. Opt. 20, 1151-1155.

Wolff G. T. and Klimisch R. L. (Eds) (1982) Particulate Carbon: Atmospheric Life Cycle. Plenum Press, New York.

Yasa Z., Amer N. M., Rosen H., Hansen A. D. A. and Novakov T. (1979) Photoacoustic investigation of urban aerosol particles. Appl. Opt. 18, 2528-2530. 